DOI 10.15393/j10.art.2016.2724

\author{
Любовь Викторовна Алексеева \\ кандидат филологических наук, \\ специиалист 1-й категории Web-лаборатории \\ филологического факультета, \\ младший научньй сотрудник \\ кафедрь русской литературь и журналистики \\ Петрозаводского государственного университета \\ (Петрозаводск, Российская Федерация) \\ lempi@mail.ru
}

\title{
КТО СКРЫВАЕТСЯ ЗА ПСЕВДОНИМОМ «Х.»?
}

Аннотация. Статья посвящена актуальной проблеме установления авторства анонимных и псевдонимных статей, опубликованных в еженедельнике «Гражданин» в период редакторства Ф. М. Достоевского, а именно - менее изученному вопросу об атрибуции статей неизвестных авторов, присылавших свои материалы в редакцию «Гражданина», в сравнении с более изученным - о причастности самого Достоевского к целому ряду анонимных заметок, рецензий, рассказов и др. На основании различных материалов, включая эпистолярное наследие Ф. М. Достоевского и его корреспондентов, архивные источники, историческую, справочную, научную литературу, установлен автор «Картинок из офицерской жизни», опубликованных в № 41 «Гражданина» за 1873 год за подписью «Х.». Им оказался Николай Александрович Шахов - офицер 1-го Лейбгвардии Екатеринославского полка Его Величества.

Ключевые слова: «Гражданин», псевдоним, атрибуция, эпистолярное наследие, Достоевский, Шахов 母 октября 1873 года в № 41 журнала «Гражданин» появилась анонимная досталъ!"» с подписью «Х.»1).

Чем этот рассказ заинтересовал редактора «Гражданина»? Составляя номер и рекомендуя текст к публикации, Ф. М. Достоевский 2 октября писал издателю журнала князю В. П. Мещерскому: «Это не разсказб даже, но всего только картинка, и какъ картинка только - она очень бы могла быть помпщена въ этомъ № Гражданина, ибо вгрно и кромп того такіе разсказики читаются съ удовольствіемь не отрываясь. Бытовая сторона богатыхъ повтосъ обицеровъ кажется схвачена вирно» ${ }^{2}$. Отметив, что "одинб только разсказб обицера, по чрезвычайной своей легкости, не могъ бъ пройти въ Гражданиню»"), Ф. М. Достоевский предполагает напечатать в номере «Гражданина» эту «всего только картинку», поместив рядом другой рассказ, «почти трагическаго содержанія» ${ }^{4}$.

«Легкость» «картинки» определяется ее содержанием - описанием одного дня из разгульной жизни петербургских офицеров, праздно проводящих время в клубах и ресторанах, живущих не по средствам, а потому всегда в поиске денег и в долгах. Отсутствие целей и занятий героев - «трех 
искателей времяпрепровождения» Хилова, Заедова, Карпинского - передают несколько фраз:

- Послушай, какъ мы проведемъ сегодня время? спросилъ Заъдовъ.

- А мы сперва по Невскому покатаемся, а потомъ пройдемся пъшкомъ, nous flanerous. $<\ldots>$

- Господа, гдъ вы сегодня вечеромъ?

- Еще не рбшили, но въроятно къ Демидросу.

Дальнейшее описание похождений офицеров представляет собой несколько эпизодов их времяпрепровождения, заключающегося в проматывании легко доставшихся денег: праздное утро поручика Заедова, покупка Хиловым дорогого хлыста с золотой ручкой, посещение ресторана в долг, поездка в игорный дом, рулетка, проигрыш, закладывание часов у ростовщика, продажа за бесценок хлыста, размышления Хилова о возможности поправить свое материальное положение выгодной женитьбой, которые заканчиваются на полуслове. Фрагментарность, бытовой характер зарисовки, выраженные в заголовке («Картинки из офицерской жизни»), подчеркивались и Ф. М. Достоевским в письме В. П. Мещерскому. В исследованиях, посвященных поэтике малых жанров: новелл, картинок и др., отмечается, что данное жанровое определение для Достоевского «является главным для содержания материала, который может заинтересовать читателя»: бытовое описание с элементами жизненного приключения, «рассказик», «бытовая сторона богатых повес» $[11,1346]$ (см. также: $[15,170-171]$; [1]; [3]; [4]; [5]; [6, 14]; [7]; [8]; [9]).

Кто же автор «Картинок из офицерской жизни», подписанных псевдонимом «Х.»?

В «Словаре псевдонимов», составленном И. Ф. Масановым, список лиц, известных под псевдонимом «Х» и «Х.» и публиковавшихся в последней трети XIX века, обширен: Хованский Алексей Андреевич, Валле-де-Бар Евгений Александрович, Вахтеров Василий Порфирьевич, Веселовский Алексей Николаевич, Грот Яков Карлович, Лучицкий Иван Васильевич, Мартынов Николай Гаврилович, Мельников Андрей Павлович и др. [13, 209-210]. Но среди них нет тех, кто публиковался в еженедельнике «Гражданин». В электронном научном издании «Словарь псевдонимов», основанном на одноименном словаре И. Ф. Масанова, данные которого были проверены, исправлены и дополнены сотрудниками Отдела библиографии и источниковедения Института русской литературы (Пушкинский Дом) РАН и Российской национальной библиотеки на основе картотеки РНБ и ряда других источников, подходящих вариантов также не находим ${ }^{5}$.

Направление поиска могут подсказать метко схваченные детали из офицерской жизни, которые явно выдают принадлежность анонимного автора к этой среде. На это указывает и Ф. М. Достоевский в письме В. П. Мещерскому («посылаю Вамъ маленькую статейку одного обицера» $\left.{ }^{6}\right)$, но имени автора в письме он не называет. 
Вероятно, по поводу «Картинок...» существовало ответное письмо В. П. Мещерского Ф. М. Достоевскому, где могло фигурировать имя их автора, но поиск среди известных писем В. П. Мещерского в архивах РО ИРЛИ и НИОР РГБ результатов не дал ${ }^{7)}$. В ближайших по датам письмах за октябрь 1873 года упоминаний о «Картинках...» нет. Если письмо и существовало, то, скорее всего, не сохранилось.

Изучение переписки Ф. М. Достоевского и его корреспондентов в период редакторства писателя в журнале «Гражданин» по рукописным материалам архивов России (РО ИРЛИ, НИОР РГБ, РНБ и др.) позволило обнаружить письмо, содержание которого раскрывает анонимного автора «Картинок из офицерской жизни». Письмо публикуется впервые.

$27 \mathrm{O} \kappa \mathrm{m}$.

Г. Редакторг,

Посылаю Вамъ продолженіе «Картинокъ обицерской жизни» при семъ предоставляю Вамъ, Милостивый Государь, полное право дплать выпуски и измпненія, какія Вы найдете нужными. При чемб ${ }^{1}$ считаю не лишнимъ Вамъ сказать слюдующее:

Типь выведенные мною всп взяты изъ дюйствительной жизни. Описанная мною свадьба была на самомъ дюлюь въ Москвп года 3, $4^{2}$ тому назадъ въ полковой иеркви Екат<еринославскаго> полка въ Москви.

Прошу фамиліи моей невыставлять, а выставить Х.

Готовый къ услугамъ

H. Шаховъ ${ }^{8}$.

В письме указаны только число и месяц его написания, но из содержания понятно, что оно относится именно к 1873 году. Судя по всему, автор планировал вскоре после выхода первой части «Картинок...» в № 41 «Гражданина» публиковать их продолжение в последующих номерах. Об этом свидетельствуют и графическое обозначение I части в самом заголовке опубликованных в журнале «Картинок...», и письмо, автор которого сообщает Ф. М. Достоевскому об отправке в редакцию нового материала для публикации. К слову, очередная часть «Картинок из офицерской жизни» так и не была опубликована.

Это короткое письмо позволяет назвать анонимного автора «Картинок...». Во-первых, он подписывается своим именем «Н. Шахов», а не псевдонимом, под которым он появился в № 41 «Гражданина», и обращается с просьбой не указывать его фамилии, «а выставить X.», тем самым подтверждая заявленный псевдоним.

Еще одна важная деталь: Н. Шахов, говоря о присланном материале,

\footnotetext{
1 Далее было начато: дол

${ }^{2}$ Было: льтъ 4, 5 - исправлено автором: года [4]/3/, [5]/4/
} 
уточняет, что описанная им свадьба действительно происходила несколько лет назад в полковой церкви «Екат<еринославскаго> полка» в Москве. Можно предположить, что автор «Картинок...» сам был свидетелем описанных им событий в Москве и, возможно, имел непосредственное отношение к упомянутому полку, исходя из принадлежности к этому разряду лиц («одинъ офицеръ»), что было обозначено в письме Ф. М. Достоевского к В. П. Мещерскому. В адрес-календарях города Москвы, дающих краткую информацию о правительственных, военных и общественных учреждениях, указано, что в это время в Москве квартировал 1-й Лейб-гренадерский Екатеринославский Его Величества полк'), именовавшийся так с 25 марта 1864 года ${ }^{10)}$. Это один из старейших привилегированных полков русской армии, основанный 30 марта 1756 года. Со времен Екатерины II над лейб-гренадерами шефствовали только царствующие особы, на что указывает приставка лейб-, добавлявшаяся к названию армейских частей, которым за заслуги жаловалось шефство императора. В 1860-1870-е годы полк находился под покровительством императора Александра, что давало привилегию дислоцироваться в Москве (см.: [14, 63]; [17], см. доп. [10, 20]) $)^{11)}$. Также в адрес-календарях обозначено место расположения полка: Покровские казармы - исторические казармы, расположенные на Покровском бульваре, $3[16,332-339]^{12}$.

Некоторые адрес-календари содержат более подробную информацию по министерствам и ведомствам, например, по интересующему нас Военному министерству - о командующем войсками округа, о штабе округа, перечень полков и воинских подразделений, дислоцировавшихся в год издания адрес-календаря в этой губернии, о лазаретах, инженерном управлении и пр. Так, в адрес-календаре Москвы за 1873 год о штабе 1-й гренадерской дивизии сказано, что в составе 1-го Лейб-гренадерского Екатеринославского Его Величества полка под командованием Эллиса Николая Вениаминовича ${ }^{13)}$ служил «Шаховъ Николай Ал<ексан $>$ др $<$ овичъ $>$, Сивцовъ Вражекъ д. Завадовскаго» ${ }^{14)}$.

Отталкиваясь от того факта, что Николай Шахов служил в 1-м Лейб-гренадерском Екатеринославском полку, т. е., скорее всего, получил соответствующее образование, находим его в списке выпускников Александровского военного училища, созданного в 1863 году в Москве на базе Александринского сиротского кадетского корпуса, где воспитывались дети-сироты штаб- и обер-офицеров, гражданских и военных чиновников из потомственных дворян ${ }^{15)}$. Училище находилось под шефством императора Александра II, а впоследствии Александра III (с 1881 года) и Николая II (с 1894 года) ${ }^{16)}$. В списке выпускников в графе «Где окончили курс» имеется помета «Гр. Уч. 3.» (гражданское учебное заведение) и указано, что Шахов Николай юнкером был выпущен в полк (VIII выпуск от 24 августа 1871 года) ${ }^{17)}$. 
Дальнейшие поиски информации о Н. Шахове - авторе «Картинок из офицерской жизни» - не дали пока дополнительных сведений. Обращение в Российский государственный военно-исторический архив (РГВИА) находится в стадии обработки запроса. Из Российского государственного исторического архива (РГИА) получен ответ, что для поиска сведений необходимо уточнение - к дворянству какой губернии был причислен Н. Шахов, поскольку в Департаменте герольдии Правительствующего Сената хранятся дела о дворянстве рода Шаховых Вологодской, Екатеринославской, Калужской, Костромской, Московской и других губерний ${ }^{18}$. После этого может быть осуществлено выявление соответствующих документов. Возможно, имеющиеся у нас на данный момент сведения о Николае Шахове будут дополнены архивными материалами.

Во всяком случае, автор «Картинок из офицерской жизни» установлен. Остается только догадываться, почему не сложилась его литературная деятельность, несмотря на лестное внимание к его произведениям Достоевского, писателя и редактора еженедельника, почему материалы, присланные им для следующих номеров «Гражданина», так и не появились в печати.

\section{ПРИМЕЧАНИЯ}

* Исследование выполнено по гранту РГНФ № 14-34-01245a2.

1) Х. Картинки изъ офицерской жизни. І. «Денегъ досталъ!» // Гражданинъ. 1873. № 41. 8 Октября [Электронный ресурс]. URL: http://philolog.petrsu.ru/fmdost/ grajd/grajdanin.html (06.03.2016). Далее цитаты приводятся по этому источнику.

${ }^{2)}$ НИОР РГБ. Ф. 93.І.6.34. Л. 3.

3) Там же. Л. 4.

4) Там же. Л. 3, 4.

${ }^{5)}$ См.: X; Х. // Электронное научное издание «Словарь псевдонимов русских писателей, ученых и общественных деятелей» (ЭНИ «Словарь псевдонимов») [Электронный pecypc]. URL: http://feb-web.ru/feb/masanov/map/15/map29679. htm (10.03.2016); URL: http://feb-web.ru/feb/masanov/map/15/map29680.htm (10.03.2016) [18].

6) НИОР РГБ. Ф. 93.І.6.34. Л. 3.

7) См.: РО ИРЛИ. Ф. 100. № 29777. 79 л.; НИОР РГБ. Ф. 93.ІІ.6.77. 29 л.

8) РО ИРЛИ. Ф. 100. № 29899. Л. 1.

9) См.: Московская памятная книжка или адресъ-календарь жителей Москвы на 1869 годъ. Ч. I, II. М.: Въ типографіи Ив. Смирнова, на Никольской ул., 1869. Ч. І. С. 26; Адресъ-календарь Москвы. 1875 годъ. С. 44.

10) Приложеніе № $1[12,11]$.

11) См. также: Екатеринославскіе лейбъ-гренадеры съ 1642-1912 гг.: ист. очеркъ. М.: Т-во скоропеч. А. А. Левенсонъ, 1912. С. 106.

${ }^{12)}$ См. наприм.: Московская памятная книжка или адресъ-календарь жителей Москвы на 1869 годъ. Ч. І. С. 26; Адресъ-календарь Москвы. 1875 годъ. С. 44. Полк размещался в Москве с 1864 по 1914 год. 
13) Адресъ-календарь Москвы, изданный по оффиціальнымъ свъдъніямъ къ 1 января 1873 г., въ пользу московскихъ дьтскихъ пріютовъ, состоящихъ подъ непосредственнымъ Ихъ Императорскихъ Величествъ покровительствомъ / под ред. А. В. Крестовоздвиженскаго. М.: Тип. Ф. Іогансонъ, 1873. С. 18.

14) Там же. С. 20.

15) См. подробнее: ([2]. Отд. I).

16) См.: ([2]. Отд. II. С. 1).

17) См. список выпускников Александровского военного училища: ([2]. Отд. II. C. 48); Александровское военное училище [Электронный ресурс]. Режим доступа: http://ria1914.info/index.php?title=\%D0\%90\%D0\%BB\%D0\%B5\%D0\%BA\%D 1\%81\%D 0\%B0\%D0\%BD\%D0\%B4\%D1\%80\%D0\%BE\%D0\%B2\%D1\%81\%D0\%BA\%D0\%BE\%D 0\%B5_\%D0\%B2\%D0\%BE\%D0\%B5\%D0\%BD\%D0\%BD\%D0\%BE\%D0\%B5_\%D1\%83 \%D1\%87\%D0\%B8\%D0\%BB\%D0\%B8\%D1\%89\%D0\%B5 (06.03.2016).

18) Возможно, среди дел Шаховых Н. А., имеющихся в архиве РГИА, есть дело и публиковавшегося в «Гражданине» офицера Николая Александровича Шахова (Ф. 1343. Оп. 33. Д. 574-585; Ф. 1343. Оп. 51. Д. 454, 542, 671; Ф. 577. Оп. 13. Д. 1589, $1590)$, который впоследствии мог покинуть военную службу и занять гражданскую должность.

\section{СПИСОК ЛИТЕРАТУРЫ}

1. Аврамец, И. Новелла Достоевского «Попрошайка» / И. Аврамец // Статьи на случай : сборник в честь 50-летия Р. Г. Лейбова [Электронный ресурc]. - URL : http://www. ruthenia.ru/leibov_50/Avramets.pdf (04.03.2016).

2. Александровское военное училище. 1863-1901 / сост. В. Кедринъ. - Москва : Тип. Г. Лисснера и А. Гешеля, 1901. - Отд. І. - 54 с. ; Отд. II. - 190 с.

3. Борисова, В. В. Малая проза Ф. М. Достоевского: принцип эмблемы / В. В. Борисова. Уфа : Башкирский государственный педагогический университет им. М. Акмуллы, 2011. - $144 \mathrm{c}$.

4. Борисова, В. В. Эмблематика в творчестве Ф. М. Достоевского / В. В. Борисова // Словесность. - Уфа, 2003. - С. 20-25.

5. Борисова, В. В. Эмблематика Достоевского / В. В. Борисова // Литературоведческий журнал. - 2002. - № 16. - С. 21-26.

6. Борисова, В. В. Эмблематический код малой прозы Ф.М.Достоевского / В.В.Борисова // Вестник Челябинского государственного университета. - 2012 . № 13 (268). - С. 14-17.

7. Габдуллина, В. И. «Блудные дети, двести лет не бывшие дома»: Евангельская притча в авторском дискурсе Ф. М. Достоевского / В. И. Габдуллина. - Барнаул : Барнаульский государственный педагогический университет, 2008. - 303 с.

8. Габдуллина, В.И. Литературно-критический дискурс в «Дневнике Писателя» Ф. М. Достоевского / В. И. Габдуллина. - Барнаул : Алтайская государственная педагогическая академия, 2013. - 171 с.

9. Габдуллина, В.И. Проблема авторского дискурса в художественной системе Ф. М. Достоевского / В. И. Габдуллина // Вестник Новосибирского государственного университета. - Сер. : История, филология. - 2007. - Т. 6. - № 2. - С. 91-97.

10. Григоровичъ, А. Перечень исторій и памятокъ войсковыхъ частей / А. Григорович. - 
Изд-е 2-е, доп. - С.-Петербургъ : Первая Женская Типографія Т-ва «Печ. Станка», 1913. - Ч. I : Гвардейскій корпусъ, гренадерскія, пъхотныя и стрьлковыя части, драгунскіе, уланскіе, гусарскіе и казачьи полки. - 96 с.

11. Денисова, А. В. Поэтика «картинки» в «Дневнике писателя» Ф. М. Достоевского / А. В. Денисова // Вестник Башкирского университета. - 2014. - Т. 19. - № 4. С. $1345-1351$.

12. Исторія Лейбъ-Гвардіи Гренадерскаго полка. 1756-1906 гг. / сост. В. К. Судравскій. С.-Петербургъ : Т-во Р. Голике и А. Вильборгъ, 1906. - Т. 1 : 1-й Гренадерскій полкъ. Лейбъ-Гренадерскій полкъ. 1756-1801 гг. - 326 с.

13. Масанов, И. Ф. Словарь псевдонимов русских писателей, ученых и общественных деятелей : в 4 т. / И. Ф. Масанов ; Всесоюз. кн. палата ; подгот. к печати Ю. И. Масанов ; ред. Б. П. Козьмин. - Т. 3 : Алфавитный указатель псевдонимов. Псевдонимы русского алфавита: Р-Я. Псевдонимы греческого и латинского алфавитов. Астронимы, цифры, разные знаки. - Москва : Изд-во Всесоюз. кн. палаты, 1958. - 415 с.

14. Семченко, Я. И. Лейб-гвардии Гренадерский полк / Я. И. Семченко // Военноисторический журнал. - 1991. - № 10. - С. 63-65.

15. Туниманов, В. А. Об анонимном фельетонном наследии Ф. М. Достоевского в годы редактирования «Гражданина» / В. А. Туниманов // Русская литература. - 1981. № 2. - С. 169-174.

16. Федосюк, Ю. Москва в кольце Садовых / Ю. Федосюк. - Москва : Московский рабочий, 1983. - 447 с.

17. Цеглеев, Э. А. Екатеринославский гренадерский полк в Отечественной войне 1812 г. и освободительном походе 1813-1814 гг. / Э. А. Цеглеев // Гуманитарные научные исследования. - 2015. - № 7 [Электронный ресурс]. - URL : http://human.snauka. ru/2015/07/12189 (28.03.2016).

18. Электронное научное издание «Словарь псевдонимов русских писателей, ученых и общественных деятелей» (ЭНИ «Словарь псевдонимов») [Электронный ресурс]. URL : http://feb-web.ru/feb/masanov/default.asp (06.03.2016). 


\title{
Lyubov V. Alekseeva
}

Ph. D. in Philology, Junior Researcher at the Department of Russian Literature and Journalism, Master of Arts of the Faculty of Philology's Web-Laboratory,

Petrozavodsk State University

(Petrozavodsk, Russian Federation)

lempi@mail.ru

\section{WHO IS BEHIND THE PSEUDONYM “X."?}

\begin{abstract}
The article considers a current problem of establishing the authorship of anonymous and pseudonymous articles published in the weekly "Grazhdanin" during F. M. Dostoevsky's editorship. Namely, it is dedicated to a less studied issue of attribution of the articles of unknown authors that used to send the materials to the editorial office of "Grazhdanin" in comparison with a more explored matter of Dostoyevsky's participation in the creation of a number of anonymous notes, reviews, stories, etc. On the basis of various materials, including epistolary heritage of F. M. Dostoevsky and his addressees by correspondence, archival sources, historical, reference, scientific literature, it was found out that the author of the "Pictures from officer life" published in No. 41 of "Grazhdanin" in 1873 and signed by "X." was Nikolai Aleksandrovich Shakhov, the officer of the Imperial Guard of the 1st Ekaterinoslav Regiment.
\end{abstract}

Keywords: "Grazhdanin", Pseudonym, "The Pictures from Officer Life", Attribution, Epistolary Heritage, Dostoevsky, Nicholai Shakhov

\section{References}

1. Avramets I. Novella Dostoevskogo «Poproshayka» [Dostoyevsky's Short Story “The Beggar Boy"]. Stat'i na sluchay: sbornik v chest' 50-letiya R. G. Leybova [Articles on the Occasion: The Collection of Articles in Honor of R. G. Leybov's 50th Anniversary]. Available at: http://www.ruthenia.ru/leibov_50/Avramets.pdf (accessed 04 March 2016).

2. Kedrin V. Aleksandrovskoe voennoe uchilishche. 1863-1901 [Aleksandrovsky Military College. 1863-1901]. Moscow, G. Lissner and A. Geshel's Printing House, 1901, part 1. 94 p.; part 2. $190 \mathrm{p}$.

3. Borisova V. V. Malaya proza F. M. Dostoevskogo: Printsip emblemy [The Small Prose of F. Dostoevsky: The Principle of an Emblem]. Ufa, M. Akmullah Bashkir State Pedagogical University Publ., 2011. 144 p.

4. Borisova V. V. Emblematika v tvorchestve F. M. Dostoevskogo [Emblems in the Works of F. Dostoevsky]. Slovesnost'. Ufa, 2003, pp. 20-25.

5. Borisova V. V. Emblematika Dostoevskogo [The Emblematic System of Dostoevsky]. Literaturovedcheskiy zhurnal [The Literary Journal], 2002, no. 16, pp. 21-26.

6. Borisova V. V. Emblematicheskiy kod maloy prozy F. M. Dostoevskogo [The Emblematic Code of the Small Prose of F. Dostoevsky]. Vestnik Chelyabinskogo gosudarstvennogo universiteta [The Bulletin of Chelyabinsk State University], 2012, no. 13 (268), pp. 14-17.

7. Gabdullina V. I. «Bludnye deti, dvesti let ne byvshie doma»: Evangel'skaya pritcha v avtorskom diskurse F. M. Dostoevskogo ["Prodigal Children Being out of Home Two Hundred Years": The Gospel Parable in the Author's Discourse of F. Dostoevsky]. Barnaul, Barnaul State Pedagogical University Publ., 2008. 303 p. 
8. Gabdullina V. I. Literaturno-kriticheskiy diskurs v «Dnevnike Pisatelya» F. M. Dostoevskogo [A Literary and Critical Discourse in "A Writer's Diary" by F. Dostoevsky]. Barnaul, Altai State Pedagogical Academy Publ., 2013. 171 p.

9. Gabdullina V. I. Problema avtorskogo diskursa v khudozhestvennoy sisteme F. M. Dostoevskogo [The Problem of an Author's Discourse in the Artistic System F. Dostoevsky]. Vestnik Novosibirskogo gosudarstvennogo universiteta. Seriya "Istoriya, filologiya" [Vestnik Novosibirsk State University. Series "History and Philology"], 2007, vol. 6, no. 2, pp. 91-97.

10. Grigorovich A. Perechen' istoriy i pamyatok voyskovykh chastey [A List of Stories and Reminder Cards of Military Units]. St. Petersburg, First Women's Printing House of Association of "Press", 1913, part 1.96 p.

11. Denisova A. V. Poetika «kartinki» v «Dnevnike pisatelya» F. M. Dostoevskogo [The Poetics of a "Picture" in F. Dostoevsky's "A Writer's Diary"]. Vestnik Bashkirskogo universiteta [The Bulletin of Bashkir State University], 2014, vol. 19, no. 4, pp. 1345-1351.

12. Sudravskiy V. K. Istoriya Leyb-Gvardii Grenaderskogo polka. 1756-1906 gg. [The History of Imperial Guard Grenadier Regiment. 1756-1906]. St. Petersburg, Tovarishchestvo R. Golike i A. Vil'borg Publ., 1906, vol. 1: the 1st Grenadier Regiment. Imperial Guard Grenadier Regiment. 1756-1801. 326 p.

13. Masanov I. F. Slovar' psevdonimov russkikh pisateley, uchenykh i obshchestvennykh deyateley: $v 4$ tomakh [The Dictionary of Pseudonyms of Russian Writers, Scientists and Public Figures: in 4 Vols]. Moscow, All-Union Book Chamber Publ., 1958, vol. 3. 415 p.

14. Semchenko Ya. I. Leyb-gvardii Grenaderskiy polk [The Imperial Guard Grenadier Regiment]. Voenno-istoricheskiy zhurnal [The Journal of Military History], 1991, no. 10, pp. 63-65.

15. Tunimanov V. A. Ob anonimnom fel'etonnom nasledii F. M. Dostoevskogo v gody redaktirovaniya «Grazhdanina» [About Anonymous Feuilletonistic Heritage of F. Dostoevsky During the Years of Editorship in "Grazhdanin”]. Russkaya literatura. 1981, no. 2, pp. 169-174.

16. Fedosyuk Yu. Moskva v kol'tse Sadovykh [Moscow in the Circle of Sadovaya Streets]. Moscow, Moskovskiy rabochiy Publ., 1983. 447 p.

17. Tsegleev E. A. Ekaterinoslavskiy grenaderskiy polk v Otechestvennoy voyne 1812 goda i osvoboditel'nom pokhode 1813-1814 godov [The Ekaterinoslav Grenadier Regiment in the Patriotic War of 1812 and the Liberation Campaign of 1813-1814]. Gumanitarnye nauchnye issledovaniya [Humanitarian Scientific Researches]. Available at: http://human.snauka. $\mathrm{ru} / 2015 / 07 / 12189$ (accessed 28 March 2016).

18. Elektronnoe nauchnoe izdanie «Slovar' psevdonimov russkikh pisateley, uchenykh $i$ obshchestvennykh deyateley» (ENI «Slovar' psevdonimov») [The Electronic Scientific Publication "Dictionary of Pseudonyms of Russian Writers, Scientists and Public Figures" (ENI "Dictionary of Pseudonyms")]. Available at: http://feb-web.ru/feb/masanov/default.asp (accessed 06 March 2016). 